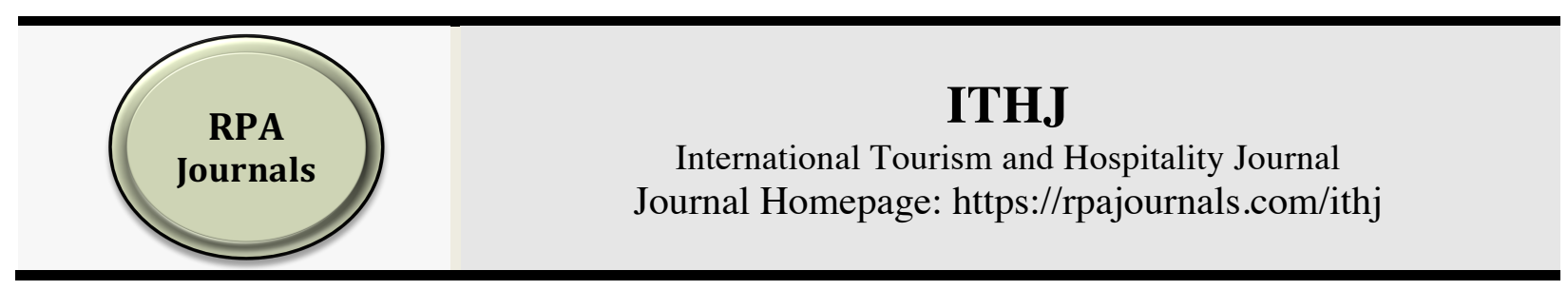

\title{
Menu Labeling in Malaysia: Who reports noticing and using it?
}

\author{
Syafiqah Rahamat ${ }^{* 1}$ \\ Susan W. Arendt ${ }^{2}$ \\ Universiti Putra Malaysia, Malaysia ${ }^{1}$ \\ Iowa State University, United States of America (USA) ${ }^{2}$
}

\begin{abstract}
Menu labeling is provided to help consumers make informed choices when eating out. This study investigated the likelihood of consumers noticing and using menu labeling in restaurants as well as the difference in actual purchase behaviour between consumers who used menu labeling and those who did not. Data collection was conducted in two restaurants that voluntarily offer menu labeling. A total of 580 consumers completed a questionnaire and checklist indicating food items they purchased. Multivariable logistic regression was conducted to estimate adjusted odds ratios (AOR) and 95\% confidence intervals (CIs) for consumers noticing and using menu labeling. A bivariate analysis was used to compare consumers' actual purchase behaviour between those who reported using and not using menu labeling. Individuals with monthly incomes MYR 4,000 to MYR 4,999 were more likely to notice menu labeling than those with monthly incomes less than MYR 1,000. Whereas, individuals 30 to 39 years old, not reporting excellent health status, and not always searching for calorie labeling were significantly less likely to use menu labeling. There were no significant difference in actual purchase behavior between those who reported using and not using menu labeling.
\end{abstract}

Keywords: Malaysia, Menu Labeling, Consumer Behavior, Sociodemographic

*Corresponding author: Syafiqah Rahamat ${ }^{1}$; E-mail: syafiqahrahamat@upm.edu.my

DOI: $\underline{\text { https://doi.org/10.37227/ithj-2020-01-39/ }}$

\section{Introduction}

Annually, it is estimated that 41 million people or $71 \%$ of total global deaths are from noncommunicable diseases (World Health Organization [WHO], 2018a). A key risk factor for noncommunicable diseases is being overweight or obesity. In 2016, 39\% of adults globally were overweight and 13\% were obese (WHO, 2018b). Over the past four decades, there has been proliferation in overweight and obesity rates for both developed and developing countries (WHO, 2017a; WHO, 2017b).

As with other developing countries, Malaysia has experienced increasing overweight and obesity rates. According to statistics published by WHO, between 1975 to 2016, overweight and obesity rates in Malaysia increased from $11.5 \%$ to $42.5 \%$ and from $1.4 \%$ to $15.6 \%$, respectively (WHO, 2017a; WHO, 2017b). Currently, Malaysia has the highest overweight and obesity rates 
across Southeast Asia (WHO, 2017a; WHO, 2017b), and approximately 50\% of the Malaysian population were either overweight or obese (Institute for Public Health, 2016).

Researchers recognized that the increase in overweight and obesity rates in Malaysia could potentially be due to dietary changes (Founier et al., 2016). A study by Bezerra and colleagues (2012) found an association between eating out and increasing overweight and obesity rates. Various studies revealed that foods offered at restaurants tend to be lower in nutritional quality (i.e., high in calories, saturated fat, sugar, and low in fiber) as compared to food prepared at home (Kant, Whiteley, \& Graubard, 2015; Lachat et al., 2012; Nguyen \& Powell, 2014; Todd, Mancino, \& Lin, 2010).

In Malaysia, eating out is becoming a popular trend especially among urban dwellers. Based on Malaysian Adult Nutrition Survey 2014, those residing in urban areas and West Malaysia (Peninsular Malaysia) ate out more than people in other areas. According to this report, between $43.0 \%$ and $47.0 \%$ of the survey participants reported that they obtained their daily meals (i.e. breakfast, lunch, and dinner) from foodservice establishments (e.g., restaurants, cafeterias, and stalls). In addition, $58.8 \%$ of participants reported that they obtained a post dinner meal from restaurants; overall stalls and restaurants were found to be the most popular places for eating out (Institute for Public Health, 2014).

To help consumers make informed choices when eating out, menu labeling has been voluntarily provided by certain restaurants in Malaysia and the Malaysian government plans to implement a mandatory federal law for menu labeling in 2025. Menu labeling contains nutrition information such as calories, saturated fat, sodium and/or carbohydrates and is posted on menus or menu boards used in restaurants (Cantu-Jungles et al., 2017). Without menu labeling, it is difficult for consumers to access information about nutrient content of food offered in restaurants and make healthful food choices (U.S. Food \& Drug Administration, 2018).

Studying the relationship between consumer characteristics' (i.e., sex, age) and the use of menu labeling in restaurants could help policy makers and foodservice operators customize menu labeling marketing and interventions to best suit consumers with different characteristics. Even so, there is no known study in Malaysia examining this relationship. Therefore, the current study examined consumers' characteristics and their associations with the likelihood of noticing and using menu labeling. The current study also examined the difference in actual purchase behavior between menu label users and non-users.

\section{Literature Review}

The United States was the first country that implemented a nationwide menu law. Whereas, other countries like Australia and Canada, have implemented menu labeling legislation in certain regions, states or cities. For instance, in Canada, under Healthy Menu Choices Act, 2015, only restaurant chains with at least 20 locations operated in Ontario, Canada are required to post calorie information on their menus (Government of Ontario, 2015). On the other hand, certain countries like Bahrain and Brazil have no mandatory requirement or policy on menu labeling, however, there is a recommendation that certain restaurants voluntarily provide menu labeling to their consumers (World Cancer Research Fund International, 2016). Countries like the United Kingdom plan to introduce menu labeling legislation in foodservice establishments (e.g., restaurants and cafes) (Department of Health and Social Care, 2018).

In Malaysia, currently, there is no mandatory policy that requires restaurants to provide menu labeling for their consumers; there are only guidelines that recommend fast food chain restaurants voluntarily provide nutrition information (e.g., nutrition information on tray liners, and/or on to go boxes). In 2016, the Malaysian government included menu labeling in the Nutrition Action Plan 2016-2025. Thus, a new law will require that certain foodservice operations in Malaysia provide menu labeling to their consumers by 2025 (Ministry of Health, 2016).

Although studies have been conducted to examine the outcome of menu labeling on consumer behaviors, there are inconclusive findings reported in the literature (Sinclair et al., 2014). Certain studies found an influence of menu labeling on consumer behaviors (Bolinger, Leslie, \& 
Sorensen, 2011; Krieger, Chan, \& Sealans, 2013; Roseman, Mather-Soulek \& Higgins, 2013; Tandon, et al. 2010), whereas other studies found no influence of menu labeling on consumer behaviors (Downs et al., 2013; Elbel et al., 2013; Holmes, et al 2013). The majority of these studies were conducted in Western and developed countries.

Studies on menu labeling are still scant in developing countries. Previous studies examined consumers' perceptions, attitudes, and intentions to use menu labeling (Din, et al., 2017; Delvarani et al., 2013; Samsudin et al., 2011; Shawky et al., 2019). However, none of these studies evaluated the difference in purchase behavior (i.e., food calories purchased) between those who used and did not use menu labeling. There were studies conducted in developed countries reporting a significant difference in number of calories purchased between those consumers who reported using labels and those who did not (Bassette et al., 2008; Dumanovsky et al., 2011; Green et al., 2015; Krieger et al., 2013). One study found no significant difference in number of calories purchased between those who used menu labeling and those who did not (Elbel, et al., 2009). Nevertheless, none of these studies took into consideration that each consumer had unique caloric needs and therefore, solely assessing total calories purchased was a major limitation. As illustration, those who are physically active, like athletes, need more calories as compared as those who have a sedentary lifestyle. Given that each individual has their own caloric needs, this current study measured consumers purchase behavior by calculating the difference between individual's food calories purchased and their own caloric needs.

Furthermore, in Malaysia, there are no available studies examining differences in consumer characteristics (e.g., sex, age) for those noticing and using menu labels. Previous studies conducted on Western populations reported that certain consumers were more likely to notice or use menu labeling. For instance, several studies found that women were more likely than men to use menu labelling (Bowers \& Suzuki, 2011; Breck, Cantor, Martinez, \& Elbel, 2014; Chen et al., 2015; Dumanovsky et al., 2011; Ellison, Lusk, \& Davis, 2013; Krieger et al., 2013; Lee-Kwan et al., 2015; Wethington et al., 2014); whereas, one study found that men are more likely to use menu labeling (Dumanovsky et al., 2010).

In terms of age, the findings of previous studies were varied across age groups (Dumanovsky et al., 2010; Ellison et al., 2013; Harnack et al., 2008; Pulos \& Leng, 2010). For example, Dumanovsky et al. (2010) reported that individuals between 25 and 44 years old are more likely to use menu labeling than those who are younger than 25 or older 44 years. There are limited studies assessing the relationship between racial and ethnic groups in noticing and using menu labeling (Harnack et al., 2008; Krieger et al. 2013; Shikdar \& Suzuki, 2018). For instance, in the United States, Harnack et al. (2008) reported that White non-Hispanic individuals were more likely to notice menu labeling.

In terms of income, evidence on the relationship between income and noticing and using menu labeling are inconclusive. Dumanovsky et al. (2011) reported that individuals with higher incomes are more likely to use menu labeling. On the other hand, other studies found no difference between income groups in using menu labeling (Krieger et al., 2013; Wethington et al., 2014). Other consumer characteristics such as frequency of menu label use and body weight status (i.e., obese, overweight, normal, underweight) have also been assessed (Lee-Kwan et al., 2016). A study by Hess and colleagues (2012) found a significant association between consumers' sociodemographics, health status, and usage of nutrition information on packaged foods.

The current study is believed to be the first one done in Malaysia examining consumer characteristic differences and the likelihood of adult consumers noticing and using menu labeling in restaurants. In particular, the current study examined the following consumer characteristics: general health, perceived body weight status, frequency of looking for calorie information on packaged foods, and frequency of using menu labeling when eating out and their associations with the likelihood of noticing and using menu labeling. The current study also examined the difference in actual purchase behavior between menu labeling users and non-users. The specific research question are: a) which consumers are more likely to notice menu labeling? b) which consumers are more likely to use menu labeling? and c) how different is actual purchase behavior between consumers who reported using menu labels and not using menu labels? 


\section{Research Methodology}

Data collection was conducted every day between June 2018 and August 2018 except during promotion weeks and public holidays (e.g. Eid celebration). Data collection was done in two outlets of a chain restaurant in Malaysia that voluntarily providing menu labeling to their consumers. One outlet was located in a mall in the Federal Territory of Putrajaya; a federal government administrative center, and another was located in a mall in Shah Alam; the capital city of Selangor State.

The current study used a non-probability convenience sampling method. Only consumers who were at least 18 years old and who dined in the study restaurant during the data collection period were eligible to participate. Consumers were approached at their tables after they ordered and an electronic tablet displaying an online questionnaire was given to the participant. After completing the online questionnaire, participants were asked to complete a hard-copy checklist indicating food items that they purchased for their own consumption.

The questionnaire began with an introductory page that had all information related to the purpose of study and procedures. There was also an agreement statement asking participants to verify that they were at least 18 years old and agreed to participate in the study. The study was approved by the University Human Subjects Review Board prior to any contact with participants. The questionnaire consisted of consumers' self-reported socio-demographics including sex, age, ethnic background, education level, as well as monthly household income. There were also questions related to participants' characteristics such as general health status, perceived body weight status, frequency looking for calorie labeling on packaged food in grocery stores, and frequency using menu labeling when dining out. The following two questions were also asked: "Today, did you notice the calorie labeling posted on the menu when purchasing your food?", and "Today, did you use the calorie labeling posted on the menu when purchasing your food?". A pilot test of the questionnaire was performed prior to use.

All statistical tests were conducted using SPSS version 24.0 software. Descriptive statistics were conducted for all variables used in the analysis. A multivariable logistic regression was conducted to estimate adjusted odds ratios (AOR) and 95\% confidence intervals (CIs) for consumers notice and use of menu labeling in the restaurant. Likelihood tests were also conducted to assess the goodness-of-fit of the regression model. A bivariate analysis was used to compare consumers' actual purchase behaviors between those who reported using and not use menu labeling.

The dependent variables were whether consumers noticed or used menu labeling when purchasing food in the study's restaurants during data collection. Selection of several of the independent variables included in current study, such as sex, age, and education level, were based on previous studies (Cheah, et al., 2015; Dumanovsky, et al., 2011; Elbel, et al., 2009). Consumers' general health status, frequency looking for calorie labeling on packaged food in grocery stores, and frequency using menu labeling when dining out were also included as independent variables in current study.

Actual purchase behavior was measured by calculating the difference between an individual's single meal caloric needs and individual's food calories purchased. The individual participant's total food calorie purchased were calculated based on the food items that participants checked on the checklist. Whereas, daily caloric needs were calculated for each participant by using the Harris Benedict equation (1919) and multiplying by individual's activity level. Then, to get individual participant's single meal caloric needs, individual's daily caloric needs were divided by three (assuming equal distribution of calories between breakfast, lunch, and dinner). The individual's caloric needs were considered as each person has different caloric needs. For instance, in general, men weigh more and have more muscle mass; therefore, they need more calories than women. 


\section{Results and Analysis}

Table 1 summarizes the sociodemographic and characteristics of the participants; 426 were female (73.4\%), and 442 were between the age of 18 and 29 years old (76.2\%). Most reported that they were Malay $(\mathrm{n}=472 ; 81.4 \%)$, and $354(61 \%)$ participants reported their highest education level as either bachelor's degree or postgraduate. There were 179 (30.9\%) participants who had monthly incomes less than MYR 1000 (less than USD 242). Of all participants, more than half indicated that their general health was good $(\mathrm{n}=318 ; 54.8 \%)$. Most respondents stated that they sometimes used calorie information on packaged foods ( $\mathrm{n}=243 ; 41.9 \%)$, and 217 (37.4\%) participants reported that they sometimes used menu labeling when eating out.

In terms of noticing and using menu labeling while the data collection was conducted, 360 (62.1\%) participants reported that they noticed menu labeling before purchasing their foods. However, only 195 (33.6\%) participants reported that they had previously used menu labeling. In assessing the difference in actual purchase behavior (purchased food calories) between those who reported using and not using menu labeling while the data collection was took place, the results indicated no significant difference between users $(\mathrm{M}=201.3$ calories, $\mathrm{SD}=422.84)$ and non-users $(\mathrm{M}=182.4$ calories, $\mathrm{SD}=402.29)$ in actual purchase behavior; $\mathrm{t}(575)=-0.526, \mathrm{p}=0.599$.

Table 1 Demographic profile of participants $(N=558$ - 578)

\begin{tabular}{lcc}
\hline \multicolumn{1}{c}{ Characteristics } & N & \% \\
\hline Sex & 152 & 26.2 \\
\hline Male & 426 & 73.4 \\
Female & 2 & 0.3 \\
Not answered (Missing) & & \\
\hline Age & 442 & 76.2 \\
\hline 18-29 years & 100 & 17.2 \\
30-39 years & 24 & 4.1 \\
40-49 years & 11 & 1.9 \\
50 years and older & 3 & 0.5 \\
Not answered (Missing) & & \\
\hline Ethnic Background & 472 & 81.4 \\
\hline Malay & 63 & 10.9 \\
Chinese & 13 & 2.2 \\
Indian & 21 & 3.6 \\
Bumiputera (Sabah/Sarawak) & 9 & 1.6 \\
Other & 2 & 0.3 \\
Not to answer (Missing) & & \\
\hline Education Level & 38 & 6.6 \\
\hline School (Elementary/ Middle/High School) & 184 & 31.7 \\
Pre-University (Form 6 / Diploma / Certificate/Foundation) & 354 & 61.0 \\
University (Bachelor's Degree / Postgraduate) & 4 & 0.7 \\
Not answered (Missing) & & \\
\hline Monthly Household Income & 179 & 30.9 \\
\hline Less than MYR 1,000 (less than USD 242) & 73 & 12.6 \\
MYR 1,000 - MYR 1,999 (USD 242 - USD 485) & 79 & 13.6 \\
MYR 2,000 - MYR 2,999 (USD 485 - USD 728) & 52 & 9.0 \\
MYR 3,000 - MYR 3,999 (USD 728 - USD 970) & 44 & 7.6 \\
MYR 4,000 - MYR 4,999 (USD 970 - USD 1213) & 131 & 22.6 \\
MYR 5,000 or more (USD 1213 or more) & 22 & 3.8 \\
Not answered (Missing) & & \\
\hline Perceived General Health & & \\
\hline & & \\
\hline
\end{tabular}




\begin{tabular}{lcc}
\hline Excellent & 153 & 26.4 \\
Good & 318 & 54.8 \\
Poor & 107 & 18.4 \\
Not answered (Missing) & 2 & 0.3 \\
\hline Searching for calories information on packaged food & 54 & \\
\hline Always & 119 & 20.5 \\
Most of the times & 243 & 41.9 \\
Sometimes & 121 & 20.9 \\
Rarely & 41 & 7.1 \\
Never & 2 & 0.3 \\
Not answered (Missing) & & \\
\hline Use menu labeling when eating out & 21 & 3.6 \\
\hline Always & 95 & 16.4 \\
Most of the times & 217 & 37.4 \\
Sometimes & 163 & 28.1 \\
Rarely & 82 & 14.1 \\
Never & 2 & 0.3 \\
Missing & & \\
\hline Did you notice menu labeling, today & 360 & 62.1 \\
\hline Yes & 218 & 37.6 \\
No & 2 & 0.3 \\
\hline Not answered (Missing) & & \\
\hline Did you use menu labeling, today & 195 & 33.6 \\
\hline Yes & 383 & 66.0 \\
No & 2 & 0.3 \\
\hline Not answered (Missing) & & \\
\hline
\end{tabular}

Table 2 reports results of the multiple logistic regression assessing the association between different consumer characteristics of those who noticed and used menu labeling when making restaurant meal purchases. The results of the logistic regression were adjusted for sex, age, education level, monthly household income, perceived general health, perceived body weight status, frequency of using menu labeling, and frequency of looking for calorie information on packaged food products. For the regression model where "noticing menu labeling" (Question: Today, did you notice menu labeling) was a dependent variable, the odds ratio of participants with monthly household income MYR 4,000 to MYR 4,999 was higher (AOR: 2.811, 95\% CI: $1.146-$ 6.890) than participants with monthly household income MYR 1,000 or less. In contrast, the odds ratio was significantly lower in noticing menu labeling (AOR: $0.529,95 \%$ CI: $0.327-0.857$ ) for the participants who reported that their general health was good as compared to those who reported their general health is excellent. Similarly, the odds ratio was significantly lower for noticing menu labeling (AOR: 0.140, 95\% CI: 0.023-0.858) of participants who reported never looking at calorie labeling when eating out as compared to the participants who reported always searching for calorie labeling when they eatout.

In terms of the logistic regression model where "using menu labeling" (Question: Today, did you use menu labeling) was a dependent variable, participants whose ages were between 30 to 39 years old had significantly lower odds in reporting using menu labeling in restaurant (AOR: $0.419,95 \%$ CI: $0.194-0.905)$ than participants who were 18 -29 years old. Participants who reported their general health as good also had a significantly lower odds of using menu labeling in restaurants (AOR: $0.508,95 \%$ CI: 0.294-0.877) than those who reported their general health as excellent.

Furthermore, participants who reported that they rarely (AOR: $0.188,95 \%$ CI: $0.044-$ 0.804), or never (AOR: $0.007,95 \%$ CI: 0.007-0.460) look for calorie labeling when eating out had 
lower odds ratios in using menu labeling in restaurant than those who always searched for calorie labeling when eating out. Similarly, those participants who reported that they most of the time (AOR: $0.368,95 \%$ CI: 0.143-0.949), sometimes (AOR: $0.176,95 \%$ CI: $0.070-0.441$ ), or rarely (AOR: $0.085,95 \%$ CI: 0.024-0.300) searched for calorie information on packaged foods had lower odds of using menu labeling in restaurants compared to those who always search for calorie information on packaged food.

Table 2 Logistic regression results assessing the association between noticing and using menu labels and demographic variables $(\mathrm{N}=558-578)$

\begin{tabular}{|c|c|c|c|c|c|c|}
\hline & \multicolumn{3}{|c|}{ Noticing Calorie Menu Labels } & \multicolumn{3}{|c|}{ Using Calorie Menu Labels } \\
\hline Explanatory Variables & $\begin{array}{c}\text { Adjusted } \\
\text { Odds } \\
\text { Ratio }\end{array}$ & $95 \% \mathrm{CI}$ & p-value & $\begin{array}{c}\text { Adjusted } \\
\text { Odds } \\
\text { Ratio }\end{array}$ & $95 \% \mathrm{CI}$ & p-value \\
\hline \multicolumn{7}{|l|}{ Sex } \\
\hline Male & 1 & & & 1 & & \\
\hline Female & 0.963 & $0.617-1.503$ & 0.868 & 0.979 & $0.574-1.670$ & 0.939 \\
\hline \multicolumn{7}{|l|}{ Age } \\
\hline $18-29$ years & 1 & & & 1 & & \\
\hline $30-39$ years & 0.960 & $0.537-1.718$ & 0.892 & $0.419 *$ & $0.194-0.905$ & 0.027 \\
\hline $40-49$ years & 0.955 & $0.320-2.847$ & 0.934 & 0.870 & $0.260-2.919$ & 0.822 \\
\hline 50 years old and over & 0.842 & $0.197-3.595$ & 0.816 & 2.085 & $0.412-10.533$ & 0.374 \\
\hline \multicolumn{7}{|l|}{ Ethnicity Background } \\
\hline Malay & 1 & & & 1 & & \\
\hline Chinese & 0.848 & $0.448-1.608$ & 0.614 & 1.536 & $0.685-3.440$ & 0.297 \\
\hline Indian & 0.952 & $0.238-3.811$ & 0.944 & 1.119 & $0.242-5.171$ & 0.885 \\
\hline $\begin{array}{l}\text { Bumiputera } \\
\text { (Sabah/Sarawak) }\end{array}$ & 2.497 & $0.746-8.360$ & 0.138 & 0.573 & $0.136-2.405$ & 0.446 \\
\hline Other & 1.214 & $0.267-5.515$ & 0.802 & 0.359 & $0.055-2.357$ & 0.286 \\
\hline \multicolumn{7}{|l|}{ Education Level } \\
\hline School & 1 & & & 1 & & \\
\hline Pre-university & 1.014 & $0.434-2.371$ & 0.974 & 0.793 & $0.280-2.247$ & 0.662 \\
\hline University & 0.889 & $0.391-2.020$ & 0.779 & 0.529 & $0.190-1.469$ & 0.222 \\
\hline \multicolumn{7}{|l|}{ Monthly Income } \\
\hline $\begin{array}{l}\text { Less than MYR 1,000 } \\
\text { (less than USD 242) }\end{array}$ & 1 & & & 1 & & \\
\hline $\begin{array}{l}\text { MYR } 1,000-\text { MYR } 1,999 \\
(U S D 242-U S D 485)\end{array}$ & 0.734 & $0.391-1.377$ & 0.335 & 1.450 & $0.678-3.099$ & 0.338 \\
\hline $\begin{array}{l}\text { MYR 2,000-MYR 2,999 } \\
(U S D 485-U S D 728)\end{array}$ & 1.087 & $0.587-2.015$ & 0.790 & 1.366 & $0.634-2.942$ & 0.426 \\
\hline $\begin{array}{l}\text { MYR 3,000-MYR 3,999 } \\
\text { (USD } 728-U S D \text { 970) }\end{array}$ & 0.994 & $0.479-2.062$ & 0.987 & 0.753 & $0.291-1.949$ & 0.559 \\
\hline $\begin{array}{l}\text { MYR 4,000-MYR 4,999 } \\
(U S D 970-U S D \text { 1213) }\end{array}$ & $2.811^{*}$ & $1.146-6.890$ & 0.024 & 2.237 & $0.821-6.095$ & 0.115 \\
\hline $\begin{array}{l}\text { MYR } 5,000 \text { or more } \\
\text { (USD } 1213 \text { or more) }\end{array}$ & 0.942 & $0.520-1.705$ & 0.843 & 1.389 & $0.669-2.881$ & 0.378 \\
\hline \multicolumn{7}{|l|}{ Perceived General Health } \\
\hline Excellent & 1 & & & 1 & & \\
\hline Good & $0.529 *$ & $0.327-0.857$ & 0.010 & $0.508 *$ & $0.294-0.877$ & 0.015 \\
\hline Fair or poor & 0.608 & $0.326-1.133$ & 0.117 & 0.577 & $0.257-1.292$ & 0.181 \\
\hline \multicolumn{7}{|l|}{$\begin{array}{l}\text { Perceived Body Weight } \\
\text { Status }\end{array}$} \\
\hline Obese & 1 & & & 1 & & \\
\hline Overweight & 0.813 & $0.340-1.942$ & 0.641 & 2.631 & $0.826-8.379$ & 0.102 \\
\hline Normal weight & $0 . .650$ & $0.279-1.515$ & 0.318 & 1.486 & $0.479-4.610$ & 0.493 \\
\hline Underweight & 0.771 & $0.268-2.216$ & 0.630 & 1.183 & $0.282-4.956$ & 0.819 \\
\hline
\end{tabular}

Use menu labeling when

eating out

Always 


\begin{tabular}{|c|c|c|c|c|c|c|}
\hline Most of the times & 1.214 & $0.216-6.827$ & 0.825 & 3.639 & $0.907-14.595$ & 0.068 \\
\hline Sometimes & 0.332 & $0.064-1.725$ & 0.190 & 0.515 & $0.138-1.923$ & 0.323 \\
\hline Rarely & 0.205 & $0.038-1.143$ & 0.071 & $0.188^{*}$ & $0.044-0.804$ & 0.024 \\
\hline Never & $0.140^{*}$ & $0.023-0.858$ & 0.034 & $0.007 *$ & $0.007-0.460$ & 0.007 \\
\hline \multicolumn{7}{|c|}{$\begin{array}{l}\text { Searching for calories } \\
\text { information on packaged } \\
\text { food }\end{array}$} \\
\hline Always & 1 & & & 1 & & \\
\hline Most of the times & 0.754 & $0.284-2.000$ & 0.579 & $0.368^{*}$ & $0.143-0.949$ & 0.039 \\
\hline Sometimes & 0.656 & $0.259-1.663$ & 0.374 & $0.176^{*}$ & $0.070-0.441$ & $<0.001$ \\
\hline Rarely & 0.377 & $0.131-1.088$ & 0.071 & $0.085^{*}$ & $0.024-0.300$ & $<0.001$ \\
\hline Never & 0.625 & $0.169-2.308$ & 0.481 & 0.225 & $0.032-1.575$ & 0.133 \\
\hline
\end{tabular}

Note: Adjusted Odds Ratios (AOR) were adjusted for gender, age, ethnicity / race, education level, monthly household income, perceived general health, perceived body weight status, frequency using menu labeling, and frequency looking for calorie information on package food; *p-value $<0.05$.

The current study was the first study in Malaysia evaluating the likelihood of consumers to notice and use menu labeling in restaurants. The findings revealed that more than $60 \%$ of individuals reported that they noticed menu labeling when making purchases. However, only $33.6 \%$ indicated that they used menu labeling when purchasing their food. These findings were similar to previous studies done in the United States (Dumanovsky et al., 2010; Green et al., 2015; Krieger et al., 2013; Pulos \& Leng, 2010; Elbel et al., 2009; Elbel et al., 2011; Wethington et al., 2014).

In assessing the likelihood of noticing menu labeling in restaurants, those with monthly household incomes between MYR 4,000 to MYR 4,999 were found to be three times more likely to notice menu labeling in restaurants as compared to those who reported that their incomes were less than MYR 1,000. This result might be explained by monetary constraints; lower income consumers may be more concerned about price information of menu items rather than nutrition information. Previous studies also found that income was associated with the likelihood of consumers noticing menu labeling, specifically higher income individuals were more likely to notice or use menu labeling in restaurants (Feng \& Fox, 2018; Green et al., 2015). In addition, a study found individuals with higher incomes spent more time viewing fat content on packaged foods as compared to individuals with lower incomes (Graham \& Jeffery, 2012).

The findings of current study also revealed that general health status was associated with noticing menu labeling in Malaysia. Those who reported that their general health status was excellent were more likely to notice and use menu labeling as compared to those who reported that their general health was good. Furthermore, those who reported never using menu labeling when they eat out were $86.0 \%$ less likely to notice and $99.3 \%$ less likely to use menu labeling on the day the study was conducted. Also, those who reported less frequently looking for calorie information on packaged grocery food were less likely to use menu labeling. One potential reason for these findings is that consumers who frequently use menu labeling and look for calorie information (past behavior) were more familiar with and confident in using information on menu labels. Past behavior has been found to have a predictive power of actions (Smith et al., 2008).

Whereas, the results of the current study indicated that age was not associated with the likelihood of consumers noticing menu labeling in restaurants. Similar to previous study, Green and colleagues (2015) found that age was not significantly associated with the likelihood of noticing menu labeling. On the other hand, in terms of likelihood using menu labeling, results of the current study indicated that consumers between 30 and 39 years old were less likely to use menu labeling in restaurants. Due to different age ranges used in every study, it is difficult to compare the results of current and previous studies. For example, Green and colleagues (2015) found those between 36 and 49 years old were least likely to use menu labeling. On the other hand, Dumanovsky and colleagues (2010), found individuals between 24 and 44 years old were more likely to use menu labeling than those who are older or younger.

In terms of actual purchase behavior, the results indicated that there was no significant difference in actual purchase behavior between those who reported using and not using menu 
labeling. The results of current study confirmed previous studies' findings that there was no significant difference in purchased food calories between users and non-users of menu labels (Elbel et al., 2009; Vadiveloo et al., 2011). One potential reason could be attributed to the fact that menu labels in the "study restaurants" did not include daily recommended caloric intake information. Daily recommended caloric intakes vary based on age, sex, and physical activity level. Without daily recommended caloric intake information, it is hard for consumers to translate the meaning of the menu labelling information. This information could help consumers compare food calories purchased with a general estimation of their caloric requirements for a day (Roberto et al., 2010), therein helping them make healthier choices. According to Kiszko and colleagues (2014), daily calorie recommendation information or statements at the point of purchase could be beneficial to most individuals who have little knowledge and understanding about calories.

Another potential reason there was no significant difference in actual purchase behavior between those who reported using and not using menu labeling may be the result of consumer preference for different nutrition information. For example, individuals who have hypertension may be more concerned about sodium content than calories. Therefore, they might not use calorie information on the menu and menu labeling may not affect their actual purchase behavior.

\section{Research Limitation and Future Direction}

This is the first known study in Malaysia that examined the association between consumers' characteristics and the use of menu labeling in restaurants. However, as with most studies, this one has potential limitations. First, this is a cross-sectional study, therefore, the causality cannot be established. This is due to the fact that in cross-sectional study, the data is collected once for each participant, therefore, patterns of the dependent variable cannot be observed overtime. Second, the current study used convenience sampling and was conducted in one restaurant chain in Malaysia, consequently, the generalizability of the findings is limited. Future research could use a longitudinal study and randomized sampling methods to increase the generalizability of the findings. Third, at the time current study was conducted, Malaysia did not have a menu labeling policy in place, thus, consumer exposure to menu labeling was limited. Results may be different after the menu labeling law has been implemented and consumers have more exposure. Therefore, future studies could examine the association between consumers' characteristics and the use of menu labeling in restaurants after the implementation of menu labeling policy in Malaysia. Lastly, there are other variables (e.g., health consciousness) not used in current study that might potentially be associated with the use of menu labeling. Therefore, future researchers could include other potential variables to examine the association between consumers' characteristics and the use of menu labeling in restaurants.

\section{Conclusions}

Given that the Malaysian government plans to implement a mandatory federal law for menu labeling in 2025, policy makers and foodservice operators could utilized the findings of the current study to customize nutrition education campaigns and interventions to best suit different consumer characteristics. Placing emphasis on education campaigns prior to implementation of the federal menu labeling law in Malaysia may increase the effectiveness of the policy. In summary, the current study found more than half study participants reported noticing menu labeling, and only half of those who noticed menu labeling used it. Those who noticed and used menu labeling in restaurants were varied by their characteristics. There was no significant difference between menu labeling users and non-users in their actual purchase behavior. Based on these findings, menu labeling education in Malaysia is paramount to increase consumers' understanding and the effectiveness of menu labeling usage.

\section{References}

Bassett, M. T., Dumanovsky, T., Huang, C., Silver, L. D., Young, C., Nonas, C., ... \& Frieden, T. R. (2008). Purchasing behavior and calorie information at fast-food chains in New York City, 2007. American Journal of Public Health, 98(8), 1457-1459. 
Bezerra, I. N., Curioni, C., \& Sichieri, R. (2012). Association between eating out of home and body weight. Nutrition Reviews, 70(2), 65-79.

Bollinger, B., Leslie, P., \& Sorensen, A. (2011). Calorie posting in chain restaurants. American Economic Journal: Economic Policy, 3(1), 91-128.

Bowers, K. M., \& Suzuki, S. (2014). Peer reviewed: Menu-labeling usage and its association with diet and exercise: 2011 BRFSS sugar sweetened beverage and menu labeling module. Preventing Chronic Disease, 11, 1-8.

Breck, A., Cantor, J., Martinez, O., \& Elbel, B. (2014). Who reports noticing and using calorie information posted on fast food restaurant menus? Appetite, 81, 30-36.

Cantu-Jungles, T. M., McCormack, L. A., Slaven, J. E., Slebodnik, M., \& Eicher-Miller, H. A. (2017). A meta-analysis to determine the impact of restaurant menu labeling on calories and nutrients (ordered or consumed) in US adults. Nutrients, 9(10), 1-18.

Cheah, Y. K., Moy, F. M., \& Loh, D. A. (2015). Socio-demographic and lifestyle factors associated with nutrition label use among Malaysian adults. British Food Journal, 117(11), 27772787.

Chen, R., Smyser, M., Chan, N., Ta, M., Saelens, B. E., \& Krieger, J. (2015). Changes in awareness and use of calorie information after mandatory menu labeling in restaurants in King County, Washington. American Journal of Public Health, 105(3), 546-553.

Delvarani, S., Ghazali, H., \& Othman, M. (2013). Factors affecting fast food consumers' intention to use menu labeling in Klang Valley, Malaysia. International Food Research Journal, 20(4), 1799-1805.

Department of Health and Social Care (2018). Closed consultation calorie labelling for food and drink served outside of the home. Retrieved February 10 2020, from https://www.gov.uk/government/consultations/calorie-labelling-for-food-and-drink-servedoutside-of-the-home

Din, N., Zahari, M. S. M., \& Shariff, S. M. (2017). Nutritional labelling in Malaysian full service restaurant menu. Journal of ASIAN Behavioural Studies, 2(2), 47-55.

Downs, J. S., Wisdom, J., Wansink, B., \& Loewenstein, G. (2013). Supplementing menu labeling with calorie recommendations to test for facilitation effects. American Journal of Public Health, 103(9), 1604-1609.

Dumanovsky, T., Huang, C. Y., Bassett, M. T., \& Silver, L. D. (2010). Consumer awareness of fast-food calorie information in New York City after implementation of a menu labeling regulation. American Journal of Public Health, 100(12), 2520-2525.

Dumanovsky, T., Huang, C. Y., Nonas, C. A., Matte, T. D., Bassett, M. T., \& Silver, L. D. (2011). Changes in energy content of lunchtime purchases from fast food restaurants after introduction of calorie labelling: Cross sectional customer surveys. BMJ, 343(d4464), 1-11.

Elbel, B., Kersh, R., Brescoll, V. L., \& Dixon, L. B. (2009). Calorie labeling and food choices: A first look at the effects on low-income people in New York City: Calorie information on menus appears to increase awareness of calorie content, but not necessarily the number of calories people purchase. Health Affairs, 28(Supp11), w1110-w1121.

Elbel, B., Mijanovich, T., Dixon, L. B., Abrams, C., Weitzman, B., Kersh, R., ... \& Ogedegbe, G. (2013). Calorie labeling, fast food purchasing and restaurant visits. Obesity, 21(11), 21722179.

Ellison, B., Lusk, J. L., \& Davis, D. (2013). Looking at the label and beyond: The effects of calorie labels, health consciousness, and demographics on caloric intake in restaurants. International Journal of Behavioral Nutrition and Physical Activity, 10(1), 21.

Feng, W., \& Fox, A. (2018). Menu labels, for better, and worse? Exploring socio-economic and race-ethnic differences in menu label use in a national sample. Appetite, 128, 223-232.

Fournier, T., Tibère, L., Laporte, C., Mognard, E., Ismail, M. N., Sharif, S. P., \& Poulain, J. P. (2016). Eating patterns and prevalence of obesity. Lessons learned from the Malaysian Food Barometer. Appetite, 107, 362-371.

Graham, D. J., \& Jeffery, R. W. (2012). Predictors of nutrition label viewing during food purchase decision making: An eye tracking investigation. Public Health Nutrition, 15(2), 189-197. 
Green, J. E., Brown, A. G., \& Ohri-Vachaspati, P. (2015). Sociodemographic disparities among fast-food restaurant customers who notice and use calorie menu labels. Journal of the Academy of Nutrition and Dietetics, 115(7), 1093-1101.

Harnack, L. J., French, S. A., Oakes, J. M., Story, M. T., Jeffery, R. W., \& Rydell, S. A. (2008). Effects of calorie labeling and value size pricing on fast food meal choices: Results from an experimental trial. International Journal of Behavioral Nutrition and Physical Activity, 5(1).

Harris, J. A., \& Benedict, F. G. (1919). A biometric study of basal metabolism in man (No. 279). Carnegie Institution of Washington.

Hess, R., Visschers, V. H., \& Siegrist, M. (2012). The role of health-related, motivational and sociodemographic aspects in predicting food label use: a comprehensive study. Public Health Nutrition, 15(3), 407-414.

Holmes, A. S., Serrano, E. L., Machin, J. E., Duetsch, T., \& Davis, G. C. (2013). Effect of different children's menu labeling designs on family purchases. Appetite, 62, 198-202.

Institute for Public Health. (2016). National Health and Morbidity Survey 2014: Malaysian Adult Nutrition Survey (MANS) Vol II: Survey Findings. Ministry of Health Malaysia, Kuala Lumpur, Malaysia.

Institute for Public Health. (2014). National Health and Morbidity Survey 2014: Malaysian Adult Nutrition Survey (MANS) Vol II: Survey Findings. Kuala Lumpur, Malaysia.

Kant, A. K., Whitley, M. I., \& Graubard, B. I. (2015). Away from home meals: Associations with biomarkers of chronic disease and dietary intake in American adults, NHANES 20052010. International Journal of Obesity, 39(5), 820-827.

Kiszko, K. M., Martinez, O. D., Abrams, C., \& Elbel, B. (2014). The influence of calorie labeling on food orders and consumption: A review of the literature. Journal of Community Health, 39(6), 1248-1269.

Krieger, J. W., Chan, N. L., Saelens, B. E., Ta, M. L., Solet, D., \& Fleming, D. W. (2013). Menu labeling regulations and calories purchased at chain restaurants. American Journal of Preventive Medicine, 44(6), 595-604.

Lachat, C., Nago, E., Verstraeten, R., Roberfroid, D., Van Camp, J., \& Kolsteren, P. (2012). Eating out of home and its association with dietary intake: A systematic review of the evidence. Obesity Reviews, 13(4), 329-346.

Lee-Kwan, S. H., Pan, L., Maynard, L., Kumar, G., \& Park, S. (2014). Restaurant menu labeling use among adults-17 states, 2012. MMWR. Morbidity and mortality weekly report, 63(27), 581.

Lin, B. H., \& Guthrie, J. F. (2012). Nutritional quality of food prepared at home and away from home, 1977-2008 (No. 1476-2016-120941).

Ministry of Health Malaysia. (2016). National Plan of Action for Nutrition of Malaysia (20162025). National Coordinating Committee on Food \& Nutrition, Malaysia.

Nguyen, B. T., \& Powell, L. M. (2014). The impact of restaurant consumption among US adults: Effects on energy and nutrient intakes. Public Health Nutrition, 17(11), 2445-2452.

Government of Ontario (2015). Healthy Menu Choices Act, 2015. S.O. 2015, Chapter 7, Schedule 1. Retrieved February 10 2020, from https://www.ontario.ca/laws/statute/15h07

Pulos, E., \& Leng, K. (2010). Evaluation of a voluntary menu-labeling program in full-service restaurants. American Journal of Public Health, 100(6), 1035-1039.

Roberto, C. A., Larsen, P. D., Agnew, H., Baik, J., \& Brownell, K. D. (2010). Evaluating the impact of menu labeling on food choices and intake. American Journal of Public Health, 100(2), 312-318.

Roberto, C. A., Haynos, A. F., Schwartz, M. B., Brownell, K. D., \& White, M. A. (2013). Calorie estimation accuracy and menu labeling perceptions among individuals with and without binge eating and/or purging disorders. Eating and Weight Disorders-Studies on Anorexia, Bulimia and Obesity, 18(3), 255-261. 
Roseman, M. G., Mathe-Soulek, K., \& Higgins, J. A. (2013). Relationships among grocery nutrition label users and consumers' attitudes and behavior toward restaurant menu labeling. Appetite, 71, 274-278.

Samsudin, A., Jusoff, K., Zaini, Z. M. M., Musa, M., Khalid, K., Ngali, N., \& Hamid, M. (2011). Customer's Perception Towards Mcdonald's Icon-Based Nutritional Labels. World Applied Sciences Journal, 12, 1-07.

Shawky, I., El Enen, M. A., \& Fouad, A. (2019). Examining Customers' Intention and Attitude Towards Reading Restaurants' Menu Labels by Using the Theory of Planned Behaviour. International Tourism and Hospitality Journal, 2(4), 1-14.

Shikdar, S., \& Suzuki, S. (2018). Racial disparities in menu-labeling usage: Analysis of the 2012 Behavioral Risk Factor Surveillance System (BRFSS) sugar-sweetened beverage and menu-labeling module. Journal of Racial and Ethnic Health Disparities, 5(3), 514-521.

Sinclair, S. E., Cooper, M., \& Mansfield, E. D. (2014). The influence of menu labeling on calories selected or consumed: a systematic review and meta-analysis. Journal of the Academy of Nutrition and Dietetics, 114(9), 1375-1388.

Smith, J. R., Terry, D. J., Manstead, A. S., Louis, W. R., Kotterman, D., \& Wolfs, J. (2008). The attitude-behavior relationship in consumer conduct: The role of norms, past behavior, and self-identity. The Journal of Social Psychology, 148(3), 311-334.

Tandon, P. S., Wright, J., Zhou, C., Rogers, C. B., \& Christakis, D. A. (2010). Nutrition menu labeling may lead to lower-calorie restaurant meal choices for children. Pediatrics, 125(2), 244-248.

Todd, J. E., Mancino, L., \& Lin, B. H. (2010). The impact of food away from home on adult diet quality. USDA-ERS Economic Research Report Paper. (EER No. 90). Retrieved February 10 2020, from https://papers.ssrn.com/sol3/papers.cfm?abstract id=1557129

U.S. Food \& Drug. (2018). Statement from FDA commissioner Scott Gottlieb, M.D., on the public health benefits from enactment of menu labeling. Retrieved February 10 2020, from https://www.fda.gov/news-events/press-announcements/statement-fda-commissioner-scottgottlieb-md-public-health-benefits-enactment-menu-labeling

Vadiveloo, M. K., Dixon, L. B., \& Elbel, B. (2011). Consumer purchasing patterns in response to calorie labeling legislation in New York City. International Journal of Behavioral Nutrition and Physical Activity, 8(51), 1-9.

Wethington, H., Maynard, L. M., Haltiwanger, C., \& Blanck, H. M. (2013). Use of calorie information at fast-food and chain restaurants among US Adults, 2009. Journal of Public Health, 36(3), 490-496.

WHO (2017a). Prevalence of overweight among adults, age 18+, 1975 - 2016 (age standardized estimate): Both sexes, 2016. Retrieved February 10 2020, from http://gamapserver.who.int/gho/interactive_charts/ncd/risk_factors/overweight/atlas.html

WHO (2017b). Prevalence of obesity among adults, ages 18+, 1975-2016 (age standardized estimate): Both sexes, 2016. Retrieved February 10 2020, from http://gamapserver.who.int/gho/interactive_charts/ncd/risk_factors/obesity/atlas.html

WHO (2018a). Noncommunicable diseases. Retrieved February 10 2020, from https://www.who.int/news-room/fact-sheets/detail/noncommunicable-diseases

WHO (2018b). Obesity and overweight. Retrieved February 10 2020, from https://www.who.int/news-room/fact-sheets/detail/obesity-and-overweight

World Cancer Research International Fund (2018). NOURISHING Framework. Nutrition label standards and regulations on the use of claims and implied claims on foods. Retrieved February 10 2020, from https://www.wcrf.org/sites/default/files/N_Nutrition-labels_0.pdf 